\title{
Interval Training and Compensation of Type 2 Diabetes
}

\author{
Petra Káfuňková1 ${ }^{*}$, Milan Kvapil ${ }^{2}$ \\ ${ }^{1}$ Clinic of Rehabilitation, Motol Hospital, Prague, Czech Republic \\ ${ }^{2}$ Internal Medicine Department, Motol Hospital, Prague, Czech Republic \\ Email: *pkaf@seznam.cz
}

How to cite this paper: Káfuňková, P. and Kvapil, M. (2017) Interval Training and Compensation of Type 2 Diabetes. Open Journal of Clinical Diagnostics, 7, 20-30. https://doi.org/10.4236/ojcd.2017.71003

Received: December 6, 2016

Accepted: February 26, 2017

Published: March 1, 2017

Copyright ( $) 2017$ by authors and Scientific Research Publishing Inc. This work is licensed under the Creative Commons Attribution International License (CC BY 4.0).

http://creativecommons.org/licenses/by/4.0/

(c) (i) Open Access

\begin{abstract}
Introduction: The constant aerobic training is traditionally considered as the best physical activity for diabetic patients. But there is existing problem with adherence (complience) of this type of exercise and toleration of the specific training intensity of exercise for such training time. The advantage of interval training is usage of higher intensity of exercise for very short time alternating with low intensity of exercise. The complex effect of this type of exercise is not mentioned in literature of type 2 diabetes too much. The aim of the study was to find the effect of interval training compound to long term participation of specific exercise program. Methods: 43 obese type 2 diabetes patients treated by diet, oral antidiabetics or insulin were randomized to 2 groups. The control group consisted of 22 patients (12 women, 10 men) with average age $67.4 \pm$ 8.4. 21 patients in main group with average age $65.29 \pm 10.67$ participated in a controlled exercise program. Before and after the study, both of 2 groups had complex internal investigation including spiroergometry. Results: Fitness parameters improved in this group of diabetics, maximal achieved power in $\mathrm{W} \cdot \mathrm{kg}^{-1}$ increased statistically significantly $p<0.05$. The level of total cholesterol decreased statistically significantly $p<0.05$; average values of LDLcholesterol decreased about $4.9 \%$ and triglycerids about $22.4 \%$; average value of HDL-cholesterol increased about 4.6\%; fasting plasma glucose levels decreased about $10.5 \%$. Percentage of body fat $p<0.05$ and diastolic blood pressure $p<0.05$ decreased based on statistics. BMI tended to decrease but WHR did not change at all. Conclusion: The physical intervention influenced statistically significantly some of the observed parameters. The interval training as a part of physical activities of diabetic patients positively intervenes in complicated system of metabolical processes.
\end{abstract}

\section{Keywords}

Interval Exercise, Type 2 Diabetes, Physical Fitness, Metabolic Control 


\section{Introduction}

Type 2 diabetes becomes one of the most serious problems of health services in developed countries. The basic therapeutic strategy remains decreasing of the need of insulin in the organism. Correction of diet and increase of physical activity are fundamental for the beginning of therapy. Physical activity (PA) of specified intensity and duration intervenes in complication of the physiological and pathophysiological processes on the central and peripheral parts of the body. The role of physical activity and its effect on diabetes have been observed for a long time. The impact of PA on metabolical control of type 2 diabetes is positive. Many studies about the relationship of exercise and type 2 diabetes, which are mentioned, in the work of Albright [1], agree that the endurant aerobic form of training improves glucose tolerance and values of glycosylated haemoglobin Alc. The regular PA also influences the lipid spectrum, decreases total cholesterol, LDL-cholesterol and increases HDL-cholesterol. There is speci- fic variability of expected effect depending on behavioral and diet arrangements, on intensity and duration of exercise, the whole time period of motion inter- venetion. Reduction of body weight is related with PA which leads to enhancement of insulin resistance and also decline of blood pressure.

The interval training belongs to the less used methods in spite that it is demons-trably effective thanks to the patient's ability to exercise at higher intensity. However, complex influence of interval form of exercise on the parameters of compensation of type 2 diabetes is not elaborated in literature [2] [3].

The aim of this study was to determine the long-term effect of exercise program consisting with the interval form of exercise to parameters of compensation of type 2 diabetes.

\section{Subjects and Methods}

This study is in accordance with the Declaration of Helsinki of the World Medical Association. The approval by the Ethics Committee of respective institution was given in.

The searching group consisted of 43 people with diabetes type 2, with hypertension and dyslipidemia. They were randomized to 2 groups. Inclusion criteria were obese patients with type 2 diabetes treated by diet, peroral antidiabetics (PAD) or insulin, age between 55 - 75 yaers old with good longterm compensation of diabetes and hypertension. Exclusion criteria were decompen- sation of diabetes, any manifestation of cardiovascular diseases meaning acute heart attack in history. Main group consisted of 21 subjects (11 men, 10 women) average was $65.29 \pm 10.67$ with duration of diabetes $14.57 \pm 9.99$. In the control group were 22 diabetics $(10$ men, 12 women) type 2 with average age $67.4 \pm 8.4$ years, duration of diabetes $16.6 \pm 5.8$. There were not any changes at treatment of type 2 diabetes during the program. A complex internal examination on the subjectsincluding biochemical determination of blood and urinewas focused on parameters of diabetic control, insulin sensitivity (ITT, HOMA index-average 
values measured parameters before and after intervention-Tables 1-4). Biochemical examination, insulin sensitivity and HOMA index: the blood samples for determination of these parameters were always realized in 8 am. InsulinHumulin R (Actrapid Penfill, Novonordisk, A/S, 3 ml, 100 m.u./ml) was used for examination HOMA index and insulin sensitivity, the blood samples for determination of glucose level, C-peptid and insulin levels were taken in 0,5 and 10 minutes of this test and for glucose level in 13, 16, 19, 22 and 25 minutes.

The HOMA P index, HOMA IR index and assimilation glucose index were calculated from measured values.

Physical fitness parameters (VO2max, Wmax) were assessed from values to the maximum intensity exercise test consist of 3 degrees correspondence to a $1 / 2,3 / 4$ and $1 \mathrm{~W} \cdot \mathrm{kg}^{-1}$ and continual increasing test to a subject's maximum intensity or some limitation of the tested subject. Parameters of the gas blood exchange and heart work were measured by Cardio $\mathrm{O}_{2}$ and $\mathrm{CPx} / \mathrm{D}$ using software BreezeEx from MedGraphic Company.

Anthropometric measuring: body mass index was calculated as the weight divided by the square of height in meters as usual, WHR was assessed from measured values-circumference of the waist and side, \% was determined as a sum of four measured values, skin lash-above $\mathrm{m}$. triceps brachii, above $\mathrm{m}$. biceps brachii, under the shoulder-blade and above the spina illiaca posterior. The measuring was done by caliper (Somet Company)in the standard way and \% body fat was assessed from the table according to J. Durnina et al.

Physical fitness program in the searching group: Interval training on bicycle ergometer, duration of the training- 50 minutes, 2 to 3 times a week, a total duration two 3-months phases which were separated by walking training for 3 months as instructed (every other day, velocity $4.5 \mathrm{~km} /$ hour). Exercise unit consisted of 5 to 10 minutes warm-up phase, then regularly changing the periods of the higher and the lower intensity of the exercise (1 minute on $80 \% \mathrm{VO}_{2}$ max $\mathrm{kg}^{-1}$ and 4 minutes on $50 \% \mathrm{VO}_{2} \max \cdot \mathrm{kg}^{-1}$ ) and 10 minutes cool-down phase.

Mode of the exercise was assessed by linear regression from submaximal test from parameters $\mathrm{VO}_{2}$ max $\cdot \mathrm{kg}^{-1}, \mathrm{~W} \cdot \mathrm{kg}^{-1}$.

Data was calculated using describing statistic methods and relationships between single values were assessed using correlating analyses. Software: Statistica.

\section{Results}

Fitness parameters improved in the main group of diabetics, maximal achieved power in W. $\mathrm{kg}^{-1}$ statistically significantly increased $p<0.05$ (Figure 1). Maximal $\mathrm{HR}$ and systolic BPhad tendency to improve in relantion to maximal power. $\mathrm{VO}_{2}$ max improved but not statistically significant. Also rest BP shows to be better, diastolic blood pressure $p<0.05$ (Figure 1) decreased statistially signifcantly. The level of total cholesterol decreased statistically significantly $p<0.05$; average values of LDL-cholesterol decreased about $4.9 \%$ and triglycerids about 22,4\%; average value of HDL-cholesterol increased about 4.6\%; Percentage of body 


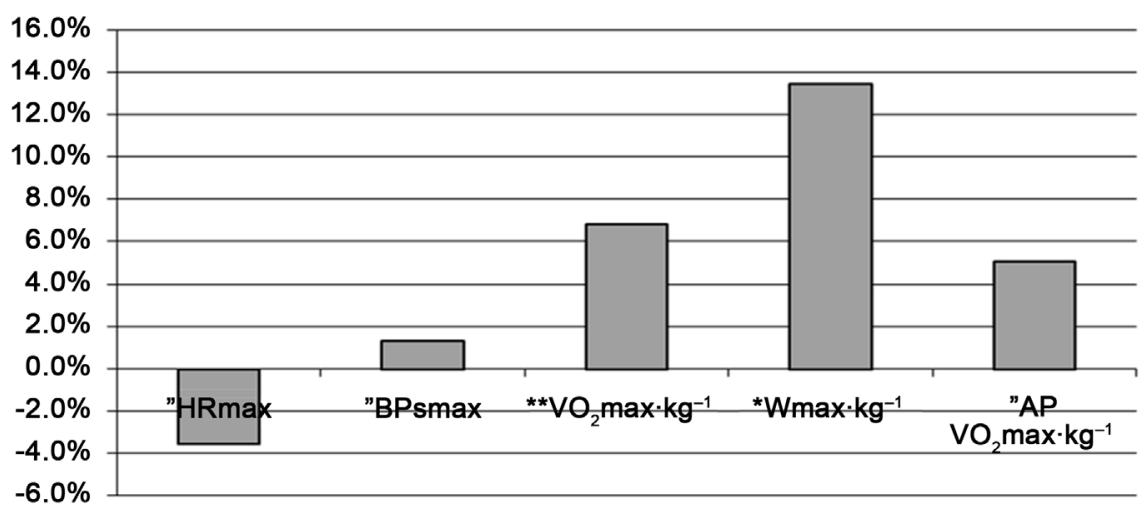

Figure 1. Parameters of physical fitness in main group. ${ }^{* *}$ statistically significant in $1 \%$, ${ }^{*}$ in $5 \%$, other in $10 \%$, "without statistical significance.

Fat $p<0.05$ (Figure 2) decreased statistially signifcantly. BMI tended to decrease but WHR did not change at all. Fasting plasma glucose levels decreased about 10.5\% (Figure 3), HbA1c became lower.Changes of insulin sensitivity (assimilation glucose index, HOMA P index) were statistically significant $p<0.05$, HOMA IR index had tendency to improving (Figure 4). The comparison of the mean value of parameters in control group befor and after program without participation of exercise indicate tendency to becomeworsebut without statistically significant changes, especially parameters of lipid and glucose metabolism. All mean values of observed parameters in both groups are mentioned in Tables 1-4.

\section{Discussion}

In this pilot study the fitness parameters statistically significant improved for maximum performance obtained in $\mathrm{W} \cdot \mathrm{kg}^{-1} / p<0.05$. Interval training also affected the metabolism of fats, like a number of studies [4] [5] [6] [7], total cholesterol significantly decreased $p<0.05$, average values of LDL fell by $4.9 \%$ and tryglycerids $22,4 \%$; average HDL increase of $4.6 \%$. Fasting glucose levels decreased by $10.5 \%$, HbA1c levels remained without significant changes. But the positive impact of PA on indicators of glycemic control such as HbAlc or fasting glucose levels shows a number of studies dealing mainly with the continuous type of training [5]-[10] resistant training [11] or the combination of both of the forms [7] [12]. Regular long-term physical training affects insulin sensitivity. Although in our study were no statistically significant changes in insulin sensitivity there is a noticeable trend towards improvement. The force component of movement contained in the interval training itself share in the improvement as well as at the resistant form of training where better results are demonstrably achieved [11] [12]. It relates to improving the muscle function and the muscle mass. The influence of insulin sensitivity can occur without significant changes in indicators of glycemic control [4]. The positive fact for interval training is that insulin sensitivity may be affected indirectly through weight loss and reduction in total body fat in the abdomen especially in combination with 


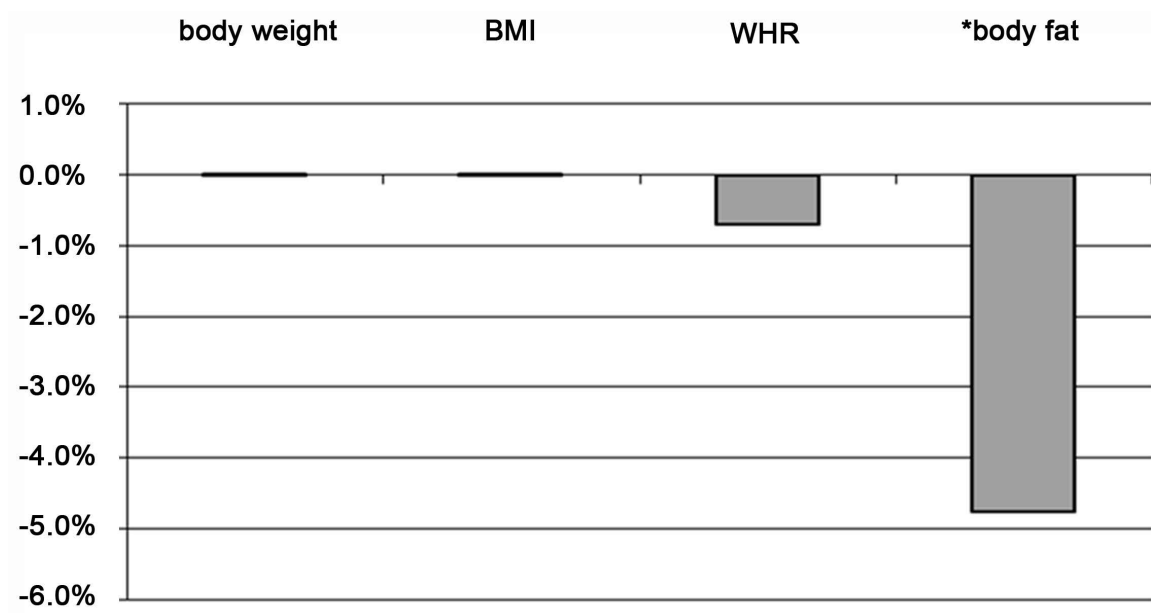

Figure 2. Anthropometric parameters in main group. ${ }^{* *}$ statistically significant in $1 \%,{ }^{*}$ in $5 \%$, other in $10 \%$, "without statistical significance.

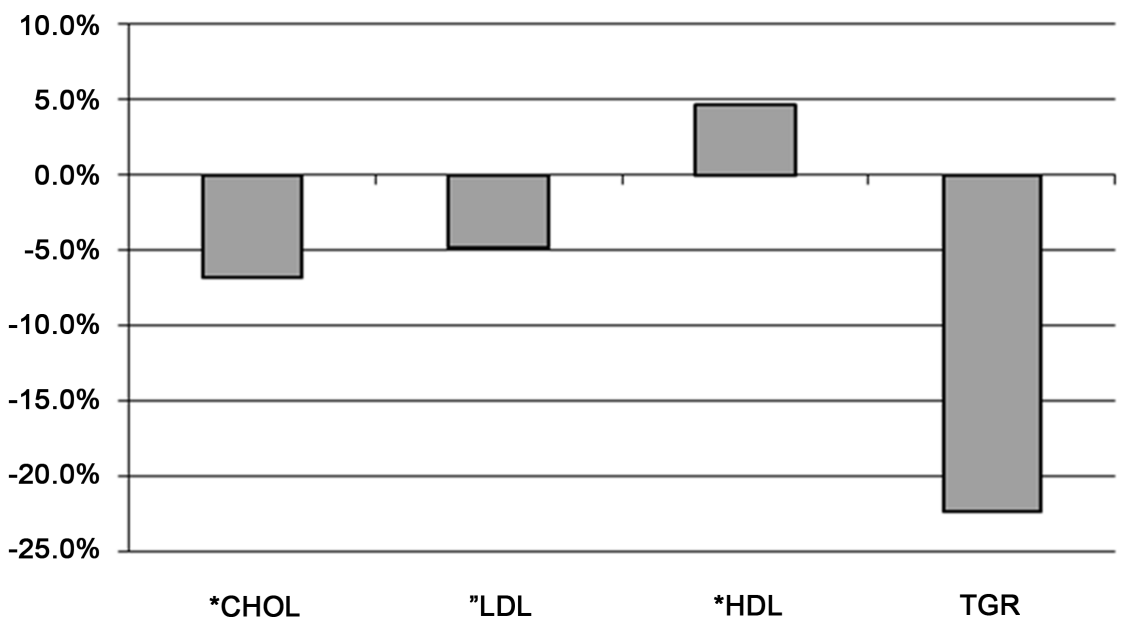

Figure 3. Parameters of lipid spectrum (main group). ${ }^{* *}$ statistically significant in $1 \%,{ }^{*}$ in $5 \%$, other in $10 \%$, --without statistical significance.

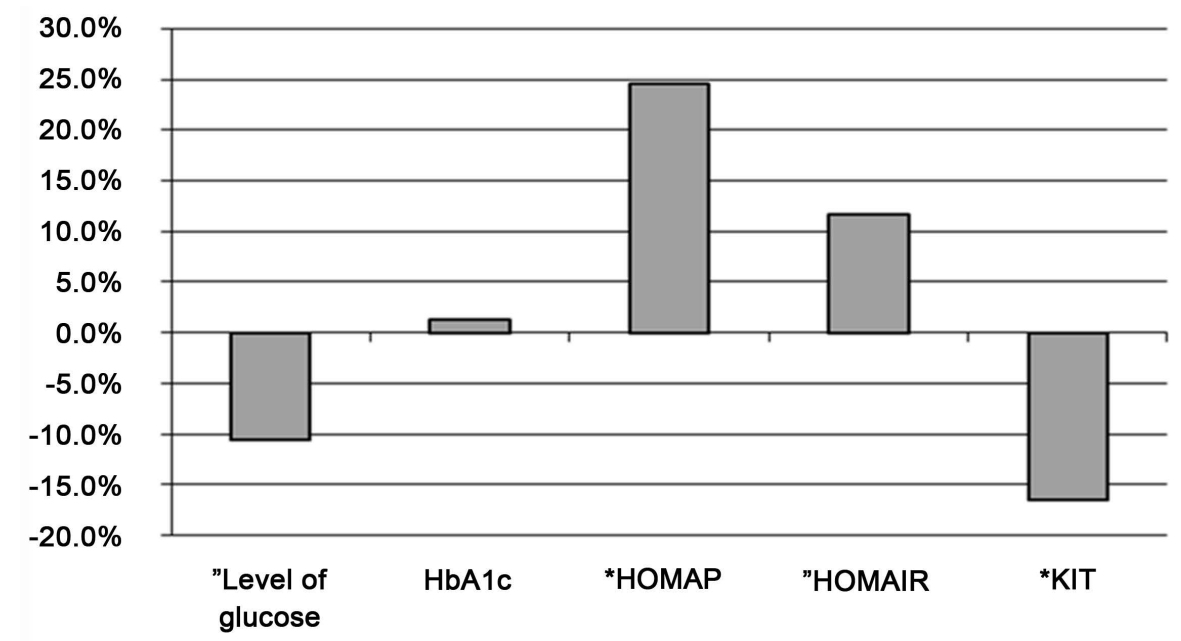

Figure 4. Parameters of insulin sensitivity and glucose control (main group). ${ }^{\star *}$ statistically significant in $1 \%,{ }^{*}$ in $5 \%$, other in $10 \%$, without statistical significance. 
Table 1. (a) Anthropometric parameters before; (b) Anthropometric parameters after.

(a)

\begin{tabular}{|c|c|c|c|c|c|c|c|c|}
\hline & \multicolumn{2}{|c|}{$\begin{array}{c}\text { BODY } \\
\text { WEIGHT [kg] }\end{array}$} & \multicolumn{2}{|c|}{$\mathrm{BMI}\left[\mathrm{kg} \cdot \mathrm{m}^{-2}\right]$} & \multicolumn{2}{|c|}{ WHR } & \multicolumn{2}{|c|}{ Body fat [\%] } \\
\hline & MG & CG & MG & CG & MG & CG & MG & CG \\
\hline Mean & 79.74 & 99.20 & 29.14 & 33.43 & 0.95 & 0.97 & 27.38 & 34.12 \\
\hline SD & 11.76 & 18.69 & 3.44 & 5.10 & 0.06 & 0.09 & 7.21 & 5.79 \\
\hline
\end{tabular}

BMI-body mass index, WHR—waist-hip ratio, SD—standard deviation, MG—main group, CG—control group.

(b)

\begin{tabular}{cccccccccc}
\hline & \multicolumn{2}{c}{$\begin{array}{c}\text { BODY } \\
\text { WEIGHT [kg] }\end{array}$} & \multicolumn{2}{c}{ BMI $\left[\mathrm{kg} \cdot \mathrm{m}^{-2}\right]$} & & \multicolumn{2}{c}{ WHR } & \multicolumn{2}{c}{ Body fat [\%] } \\
\cline { 2 - 9 } & MG & CG & MG & CG & MG & CG & MG & CG \\
\hline Mean & 80.00 & 98.13636 & 28.55 & 33.56 & 0.94 & 0.96 & 26.47 & 33.45 \\
SD & 11.76 & 15.9503 & 2.81 & 4.64 & 0.05 & 0.092 & 5.96 & 6.75 \\
\hline
\end{tabular}

BMI-body mass index, WHR - waist-hip ratio, SD—standard deviation, MG-main group, CG-control group.

Table 2. (a) Parameters of physical fitness before; (b) Parameters of physical fitness after.

(a)

\begin{tabular}{|c|c|c|c|c|c|c|c|c|c|c|c|c|}
\hline & \multicolumn{2}{|c|}{$\begin{array}{l}\text { Rest BPs } \\
{[\mathrm{mmHg}]}\end{array}$} & \multicolumn{2}{|c|}{$\begin{array}{l}\text { Rest BPd } \\
{[\mathrm{mmHg}]}\end{array}$} & \multicolumn{2}{|c|}{ HRmax } & \multicolumn{2}{|c|}{$\begin{array}{l}\text { BPs max } \\
{[\mathrm{mmHg}]}\end{array}$} & \multicolumn{2}{|c|}{$\begin{array}{c}\mathrm{VO}_{2} \\
\mathrm{max} \cdot \mathrm{kg}^{-1} \\
{\left[\mathrm{~kg} \cdot \mathrm{ml}^{-1}\right]}\end{array}$} & \multicolumn{2}{|c|}{$\mathrm{Wmax} \cdot \mathrm{kg}^{-1}$} \\
\hline & MG & CG & MG & CG & MG & CG & MG & CG & MG & CG & MG & CG \\
\hline Mean & 153.81 & 136.13 & 90.95 & 83.41 & 143.05 & 147.45 & 215.95 & 210.68 & 21.00 & 20.33 & 1.92 & 1.86 \\
\hline SD & 18.36 & 16.32 & 7.52 & 7.77 & 24.17 & 19.75 & 23.70 & 24.12 & 4.58 & 4.81 & 0.52 & 0.53 \\
\hline
\end{tabular}

Rest BPs-resting systolic blood pressure, Rest BPd-resting diastolic blood pressure, HRmax-maximal heart rate, $\mathrm{BPs} \max -$ maximum blood pressure, $\mathrm{VO}_{2}$ max $\cdot \mathrm{kg}^{-1}$-maximal demand of oxygen on kilogram of body weight $\mathrm{Wmax} \cdot \mathrm{kg}^{-1}$ - maximum power expressed watts on kilogram of body weight, $\mathrm{SD}$-standard deviation, MG-main group, CG-control group.

(b)

\begin{tabular}{|c|c|c|c|c|c|c|c|c|c|c|c|c|}
\hline & \multicolumn{2}{|c|}{$\begin{array}{l}\text { Rest BPs } \\
{[\mathrm{mmHg}]}\end{array}$} & \multicolumn{2}{|c|}{$\begin{array}{l}\text { Rest BPd } \\
{[\mathrm{mmHg}]}\end{array}$} & \multicolumn{2}{|c|}{ HRmax } & \multicolumn{2}{|c|}{$\begin{array}{l}\text { BPs max } \\
{[\mathrm{mmHg}]}\end{array}$} & \multicolumn{2}{|c|}{$\begin{array}{c}\mathrm{VO}_{2} \\
\mathrm{max} \cdot \mathrm{kg}^{-1} \\
{\left[\mathrm{~kg} \cdot \mathrm{ml}^{-1}\right]}\end{array}$} & \multicolumn{2}{|c|}{$\mathrm{Wmax} \cdot \mathrm{kg}^{-1}$} \\
\hline & MG & CG & MG & CG & MG & CG & MG & CG & MG & CG & MG & CG \\
\hline Mean & 150.48 & 134.55 & 85.48 & 83.86 & 138 & 149.55 & 218.81 & 214.77 & 22.44 & 20.92 & 2.18 & 2.04 \\
\hline SD & 21.67 & 16.68 & 8.2 & 6.35 & 23.13 & 19.59 & 17.53 & 26.57 & 4.92 & 5.82 & 0.57 & 0.67 \\
\hline
\end{tabular}

Rest BPs-resting systolic blood pressure, Rest BPd—resting diastolic blood pressure, HRmax-maximal heart rate, $\mathrm{BPs} \max$ - maximum blood pressure, $\mathrm{VO}_{2} \max \cdot \mathrm{kg}^{-1}$-maximal demand of oxygen on kilogram of body weight $\mathbf{W}$ max $\cdot \mathbf{k g}^{-1}$ — maximum power expressed watts on kilogram of body weight, SD—standard deviation, MG—-main group, CG—control group. 
Table 3. (a) Parameters of lipid spectrum before; (b) Parameters of lipid spectrum after.

(a)

\begin{tabular}{ccccccccc}
\hline & \multicolumn{2}{c}{$\begin{array}{c}\text { CHOL } \\
{\left[\mathrm{mlmol} \cdot \mathrm{l}^{-1}\right]}\end{array}$} & \multicolumn{2}{c}{$\begin{array}{c}\text { LDL } \\
{\left[\mathrm{mlmol} \cdot \mathrm{l}^{-1}\right]}\end{array}$} & \multicolumn{2}{c}{$\begin{array}{c}\text { HDL } \\
{\left[\mathrm{mlmol} \cdot \mathrm{l}^{-1}\right]}\end{array}$} & \multicolumn{2}{c}{$\begin{array}{c}\text { TGR } \\
{\left[\mathrm{mlmol} \cdot \mathrm{l}^{-1}\right]}\end{array}$} \\
\cline { 2 - 10 } & MG & CG & MG & CG & MG & CG & MG & CG \\
\hline Mean & 4.69 & 4.89 & 3.46 & 3.37 & 1.38 & 1.17 & 2.36 & 2.19 \\
SD & 0.89 & 1.05 & 0.81 & 0.86 & 0.29 & 0.21 & 0.68 & 0.64 \\
\hline
\end{tabular}

CHOL — total cholesterol, LDL — low density lipoprotein, HDL — high density lipoprotein, TGR — triglycerids, SD-standard deviation, $\mathrm{MG}$ - main group, $\mathrm{CG}-$ control group.

(b)

\begin{tabular}{ccccccccc}
\hline & \multicolumn{2}{c}{$\begin{array}{c}\text { CHOL } \\
{\left[\mathrm{mlmol} \cdot \mathrm{l}^{-1}\right]}\end{array}$} & \multicolumn{2}{c}{$\begin{array}{c}\text { LDL } \\
{\left[\mathrm{mlmol} \cdot \mathrm{l}^{-1}\right]}\end{array}$} & \multicolumn{2}{c}{$\begin{array}{c}\text { HDL } \\
{\left[\mathrm{mlmol} \cdot \mathrm{l}^{-1}\right]}\end{array}$} & \multicolumn{2}{c}{$\begin{array}{c}\text { TGR } \\
{\left[\mathrm{mlmol} \cdot \mathrm{l}^{-1}\right]}\end{array}$} \\
\cline { 2 - 10 } & MG & CG & MG & CG & MG & CG & MG & CG \\
\hline Mean & 5.23 & 5.20 & 3.39 & 3.26 & 1.45 & 1.08 & 1.65 & 2.25 \\
SD & 0.61 & 0.98 & 0.58 & 0.92 & 0.36 & 0.20 & 0.59 & 0.63 \\
\hline
\end{tabular}

CHOL — total cholesterol, LDL_low density lipoprotein, HDL_high density lipoprotein, TGR — triglycerids, SD—standard deviation, $\mathrm{MG}$ - main group, $\mathrm{CG}$ - control group.

Table 4. (a) Parameters of the insulin sensitivity and glucose control before; (b) Parameters of the insulin sensitivity and glucose after.

(a)

\begin{tabular}{|c|c|c|c|c|c|c|c|c|c|c|}
\hline & \multicolumn{2}{|c|}{ HOMA P } & \multicolumn{2}{|c|}{ HOMA IR } & \multicolumn{2}{|c|}{$\begin{array}{c}\text { KIIT } \\
{\left[\% \cdot \mathrm{min}^{-1}\right]}\end{array}$} & \multicolumn{2}{|c|}{$\begin{array}{c}\text { Level of } \\
\text { glucose } \\
{\left[\mathrm{mlmol} \cdot \mathrm{l}^{-1}\right]}\end{array}$} & \multicolumn{2}{|c|}{ HbAlc } \\
\hline & MG & CG & MG & CG & MG & CG & MG & CG & MG & CG \\
\hline Mean & 54.90 & 64.58 & 0.58 & 0.63 & 2.79 & 2.67 & 9.91 & 8.32 & 5.92 & 5.92 \\
\hline SD & 61.04 & 38.10 & 0.60 & 0.26 & 1.09 & 1.08 & 3.25 & 2.60 & 1.50 & 2.16 \\
\hline
\end{tabular}

SD-standard deviation, HOMA P-homeostatic model analysis, KITT-assimilation glucose index, HbAlc-glycosylated hemoglobin Alc, MG—main group, CG—control group.

(b)

\begin{tabular}{cccccccccccc}
\hline & HOMA P & HOMA IR & \multicolumn{2}{c}{$\begin{array}{c}\text { KIIT } \\
{\left[\% \cdot \mathrm{min}^{-1}\right]}\end{array}$} & \multicolumn{2}{c}{$\begin{array}{c}\text { Level of } \\
\text { glucose } \\
{\left[\mathrm{mlmol} \cdot \mathrm{l}^{-1}\right]}\end{array}$} & HbA1c \\
\cline { 2 - 11 } & MG & CG & MG & CG & MG & CG & MG & CG & MG & CG \\
\hline Mean & 67.11 & 64.63 & 0.82 & 0.62 & 2.23 & 2.75 & 8.03 & 8.46 & 5.37 & 5.91 \\
SD & 63.98 & 38.07 & 0.83 & 0.25 & 1.02 & 1.05 & 2.27 & 2.72 & 1.25 & 1.82 \\
\hline
\end{tabular}

SD-standard deviation, HOMA P-homeostatic model analysis, KITT-assimilation glucose index, HbA1c-glycosylated hemoglobin A1c, MG-main group, CG-control group.

adequate movement [13]. Comparing anthropometric para- meters before and after the motion program is found to be significantly decreased values of percent body fat $p<0.05$. Body fat is considered a better predictor of CVD risk than aerobic fitness [14]. In contrast to other studies [5] [6] [7] [9] [10] [15] [16], BMI, WHR remained without statistically significant changes. The changes are 
reflected more in the combination of physical activity and diet appropriately chosen [10] but in our study was not carried out targeted nutritional intervention, only the consultation and recommendations for changes in dietary habits.

The resulting effect of regular physical activity of some magnitude and duration is reduction of resting and submaximal values of heart rate and blood pressure. Praet et al. [2] combines a form of resistance training with interval form with a resulting positive effect on the muscle function and the blood pressure. In our study we found statistically significant decrease in diastolic blood pressure, sleep $p<0.05$. Peripheral vascular resistance is reduced and blood flow to muscle is increased [17] [18], which may be due to a reduction or increase in vasoconstrict tone or vasodilatory endothelial fiction. Physical training reduces the sympathetic nervous system activity [19] [20] and corrects the heart rate variability and heart rate.

Summation of responses to periodic physical activity and adaptive changes occur to improve the economy of cardiac work and glycemic control of type 2 diabetes.Generally, it is recommended a combination of endurance forms of exercise with resistant forms of training based on American Diabetes Association and clinical studies, the minimum energy expenditure should amount to $1000 \mathrm{kcal}$ per week [1] [21]. Continuous aerobic physical exercise (walking, riding a bicycle ergometer or on the bike and run) has a significant influence on physical fitness expressed $\mathrm{VO}_{2} \max$ [4] [7] [10] [15] [22] [23] [24]. However, it must be attained a certain level of intensity of exercise (between $60 \%-85 \% \mathrm{VO}_{2}$ max) [5] [25]. In most published studies agree on mild to moderate a load intensity of $40 \%-60 \% \mathrm{VO}_{2}$ max length of $30-90$ minutes, $2-6 \times$ a week. The intensity of the exercise equivalent to $60 \% \mathrm{VO}_{2}$ max is considered sufficient to bring about the changes related to fitness [25] [26], it is not always achieved significant changes in parameters of glycemic control [27] [28] yet. Achieve and sustain a particular intensity above the load may be limitations on the implementation and the effect of physical activity for patients with complications or low fitness. Interval training which is less used by the type of training for diabetics contains a short phase of work alternating with short phases of rest or rotation of the exercise of a higher intensity and exercise of less intensity according to the patient's fitness. The result is to achieve greater stimulation of the muscles and cardiovascular system than during training at steady state. It is especially suitable for patients with low aerobic capacity.

Limitations of exercise and determination of the optimal intensity are dependent on anamnestic datas, physical and mental dispositions of the patient and especially on results of the exercise test with analysis of ventilation parameters. Also there are some other facts affecting the results of the study such as inhomogeneity and a small sample of diabetics. Important roles as well as the limitations of success is the motivation and adherence to a given motion program.

\section{Conclusions}

Physical intervention significantly influenced some of the parameters studied. 
Physical fitness increased in study group, and the parameters of lipid and glycemic control improved.

Interval training positively affects the complex system of metabolic processes due to the large proportion of the continuously alternating sections of loads of lower and higher intensity. It contains both static and dynamic component, and it combines elements of endurance and resistant forms of training. Interval training allows you to achieve and maintain an overall higher intensity of the exercise and the anticipated, improved metabolic and cardiovascular effects. The motivation and adherence to a given intervention program play an important role in success. Interval training is better structured and more interesting for patients better time tolerated due to changes in intensity during training without interruption. According to our results, interval training is very good and effective alternative to diversity training for patient.

\section{Acknowledgements}

This work was performed without any special financial support or technical assistance. The interventional project was part of standartized process of the therapy for patiens with type 2 diabetes who wanted to participate on special offered programms of physical therapy.

\section{References}

[1] Albright, A., Franz, M., Hornsby, G., Kriska, A., Marrero, D., Ullrich, I. and Verity, L.S. (2000) American College of Sports Medicine Position stand. Exercise and Type 2 Diabetes. Medicine \& Science in Sports \& Exercise, 32, 1345-1360. https://doi.org/10.1097/00005768-200007000-00024

[2] Praet, S.F., Junkers, R.A., Schep, G., Stehouwer, C.D., Kuipers, H., Keizer, H.A. and Van Loon, L.J. (2008) Long-Standing, Insulin-Treated Type 2 Diabetes Patiens with Complications Reskond Well to Short-Term Resistence and Interval Exercise Training. European Journal of Endocrinology, 158, 163-172. https://doi.org/10.1530/EJE-07-0169

[3] Eriksson, G.J. (1999) Exercise and Treatment of Type 2 Diabetes Mellitus. Sports Medicine, 27, 381-391. https://doi.org/10.2165/00007256-199927060-00003

[4] Wagner, H., Degerbled, M., Thorell, A., Nygren, J., Ståhle, A., Kuhl, J., Brismar, T.B., Ohrivik, J., Efendic, S. and Båvenhol, P.N. (2006) Combined Treatment with Exercise Training and Acarbose Improves Metabolic Control and Cardiovascular Risk Factor Profile in Subjects with Mild Type 2 Diabetes. Diabetes Care, 29, 14711477. https://doi.org/10.2337/dc05-2513

[5] Alam, S., Stolinski, M., Pentecost, C., Borojerdi, M.A., Jones, R.H., Sonksen, P.H. and Umpleby, A.M. (2004) The Effect of a Six-Month Exercise Program on Very Low-Density Lipoprotein Apolipoprotein B Secretion in Type 2 Diabetes. The Journal of Clinical Endocrinology \& Metabolism, 89, 688-694. https://doi.org/10.1210/jc.2003-031036

[6] Kelly, G.A. and Kelly, K.S. (2007) Effects of Aerobic Exercise on Lipids and Lipoproteins in Adults with Type 2 Diabetes. Public Health, 121, 643-655. https://doi.org/10.1016/j.puhe.2007.02.014

[7] Sigal, R.J., Kenny, G.P., Boulé, N.G., Wells, G.A., Prud'Homme, D., Fortier, M., Reid, R.D., Tulloch, H., Coyle, D., Phillips, P., Jennings, A. and Jaffey, J. (2007) 
Effects of Aerobic Training, Resistance Training, or Both on Glycemic Kontrol in Type 2 Diabetes: A Randomized Trial. Annals of Internal Medicine, 18, 357-369. https://doi.org/10.7326/0003-4819-147-6-200709180-00005

[8] Goldhaber-Fiebert, J.D., Goldhaber-Fiebert, S.N., Tristan, M.L. and Nathan, D.M. (2003) Randomized Controlled Community-Based Nutrition and Exercise Intervention Improves Glycemia and Cardiovascular Risk Factors in Type 2 Diabetic Patients in Rural Costa Rica. Diabetes Care, 26, 24-29.

https://doi.org/10.2337/diacare.26.1.24

[9] Boulé, N.G., Haddad, E., Keny, G.P., Wells, G.A. and Sigal, R.J. (2001) Effects of Exercise on Glycemic Control and Body Mass in Type 2 Diabetes Mellitus. JAMA, 286, 1218-1227. https://doi.org/10.1001/jama.286.10.1218

[10] Cuff, D.J., Meneilly, G.S., Martin, A., Ignaszewski, A., Tildesly, H.D. and Frolich, J.J. (2003) Effective Exercise Modality to Reduce Insulin Resistance in Women with Type 2 Diabetes. Diabetes Care, 26, 2977-2982. https://doi.org/10.2337/diacare.26.11.2977

[11] Brooks, N., Layne, J.E., Gordon, P.L., Roubenoff, R., Nelson, M.E. and CastanedaSceppa, C. (2006) Strength Training Improves Musile Duality and Insulin Sensitivity in Hispanic Older Adults with Type 2 Diabetes. International Journal of Medical Sciences, 18, 19-27.

[12] Cauza, E., Anusch-Enserer, U., Strasser, B., Ludvik, B., Metz-Schimmerl, S., Pacini, G., Wagner, O., Georg, P., Prager, R., Kostner, K. and Dunky, A. (2005) The Relative Benefits of Endurance and Strength Training on Metabolit Factors and Musile Function of People with Type 2 Diabetres Mellitus. Archives of Physical Medicine and Rehabilitation, 88, 1527-1533. https://doi.org/10.1016/j.apmr.2005.01.007

[13] Ryan, A.S. (2000) Insulin Resistence with Aging: Effects of Diet and Exercise. Sports Medicine, 30, 327-346. https://doi.org/10.2165/00007256-200030050-00002

[14] Christou, D.D., Ventile, C.L., Desouza, C.A., Seala, D.R. and Gates, P.E. (2005) Fatness Is a Berger Predictor of Cardiovascular Disease Risk Profile Than Aerobic Fitness in Healthy Men. Circulation, 111, 1904-1914. https://doi.org/10.1161/01.CIR.0000161818.28974.1A

[15] Dela, F., von Linstow, M.E., Mikines, K.J. and Galbo, H. (2004) Physical Training May Enhance $\beta$-Cell Function in Type 2 Diabetes. American Journal of Physiology: Endocrinology and Metabolism, 287, E1024-E1031. https://doi.org/10.1152/ajpendo.00056.2004

[16] The Look AHEAD Research Group (2007) Reduction in Weight and Cardiovascular Disease Risk Factors in Individuals with Type 2 Diabetes. Diabetes Care, 30, 13741383. https://doi.org/10.2337/dc07-0048

[17] Sullivan, M.J., Higginbotham, M.B. and Cobb, F.R. (1988) Exercise Training in Patiens with Severe Left Ventricular Dysfunction. Hemodynamic and Metabolic Effects. Circulation, 78, 506-515. https://doi.org/10.1161/01.CIR.78.3.506

[18] Demopoulos, L., Bijou, R., Fergus, I., Jones, M., Strom, J. and Lejemtel, T.H. (1997) Exercise Training in Patiens with Severe Congestive Heart Failure: Enhancing Peak Aerobic Capacity while Minimizing the Increase in Ventricular Wall Stress. Journal of the American College of Cardiology, 29, 597-603. https://doi.org/10.1016/S0735-1097(96)00526-8

[19] Coats, A.J.S., Adamopoulos, S., Meyer, T.E., et al. (1990) Effect of Physical Training in Chronic Heart Failure. The Lancet, 335, 63-66. https://doi.org/10.1016/0140-6736(90)90536-E

[20] Killavouri, K., Toivonen, L., Naveri, H. and Leinonen, H. (1995) Reversal of 
Autonomic Derangemenents by Physical Training in Chronic Hert Failure Assessed by Heart Rate Variability. European Heart Journal, 16, 490-495.

[21] Ruderman, N. and Devlin, J.T. (1995) The Health Professional's Guide to Diabetes and Exercise. American Diabetes Association, Alexandria, 133-197, 265-305.

[22] Short, K.R., Vittone, J.L., Bigelow, M.L., Proctor, D.N., Rizza, R.A., CoenenSchimke, J.M. and Nair, K.S. (2003) Impact of Aerobic Exercise Training on AgeRelated Changes in Insulin Sensitivity and Muscle Oxidative Capacity. Diabetes, 52, 1888-1896. https://doi.org/10.2337/diabetes.52.8.1888

[23] Lee, S., Kuk, J.L., Davidson, L.E., Hudson, R., Hudson, R., Kilpatrick, K., Graham, T.E. and Ross, R. (2005) Exercise without Weight Loss Is an Effective Strategy for Obesity Reduction in Obese Individuals with and without Type 2 Diabetes. Journal of Applied Physiology, 99, 1220-1225.

https://doi.org/10.1152/japplphysiol.00053.2005

[24] Duncan, G.E., Anton, S.D., Sydeman, S.J., Newton, R.L.,Corsica, J.A., Durning, P.E., Ketterson, T.U., Martin, A.D., Limacher, M.C. and Perri, M.G. (2005) Prescribing Exercise at Varied Levels of Intensity and Frequency: A Randomized Trial. Archives of Internal Medicine, 165, 2362-2369. https://doi.org/10.1001/archinte.165.20.2362

[25] Poirier, P., Trembley, A., Broderick, T.,Catellier, C., Tancrède, G. and Nadeau, A. (2002) Impact of Moderate Aerobic Exercise Training on Insulin Sensitivity in Type 2 Diabetic Men Treated with Oral Hypoglycemic Agents: Is Insulin Sensitivity Enhanced Only in Nonobese Subjects? Medical Science Monitor, 8, CR59-CR65.

[26] Houmard, J.A., Tanner, C.J., Slentz, C.A., Duscha, B.D., McCartney, J.S. and Kraus, W.E. (2004) Effect of the Volume and Intensity of Exercise Training on Insulin Sensitivity. Journal of Applied Physiology, 96, 101-106. https://doi.org/10.1152/japplphysiol.00707.2003

[27] Eriksen, L., Dahl-Petersen, I., Haugaard, S.B. and Dela, F. (2007) Comparison of the Effect of Multiple Short-Duration with Single Long-Duration Exercise Sessions on Glukose Homeostasis in Type 2 Diabetes Mellitus. Diabetologia, 50, 2245-2253. https://doi.org/10.1007/s00125-007-0783-0

[28] Ivy, J.L. (1997) Role of Exercise Training in Prevention and Treatment of Insulin Resistence and Non-Insulin-Dependant Diabetes Mellitus. Sports Medicine, 24, 321-336. https://doi.org/10.2165/00007256-199724050-00004

\section{Submit or recommend next manuscript to SCIRP and we will provide best service for you:}

Accepting pre-submission inquiries through Email, Facebook, LinkedIn, Twitter, etc. A wide selection of journals (inclusive of 9 subjects, more than 200 journals)

Providing 24-hour high-quality service

User-friendly online submission system

Fair and swift peer-review system

Efficient typesetting and proofreading procedure

Display of the result of downloads and visits, as well as the number of cited articles

Maximum dissemination of your research work

Submit your manuscript at: http://papersubmission.scirp.org/

Or contact ojcd@scirp.org 